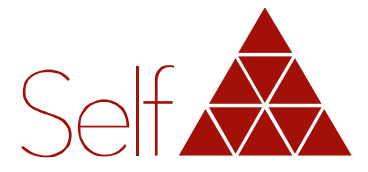

Revista do Instituto Junguiano de São Paulo

\title{
Reflexões sobre o conflito entre religião e homossexualidade
}

\section{Guilherme Silva GONÇALVES}

São Paulo, SP, Brasil.

\section{Resumo}

Este artigo investiga alguns aspectos psicológicos que influenciaram o conflito entre homossexualidade e religião ao longo da história, tendo a psicologia analítica de C. G. Jung como referência teórica principal. Essa questão é relevante, pois a presente divisão ideológica no Brasil pode levar os que apoiam a comunidade LGBTI+ a se afastarem dos símbolos religiosos. $\mathrm{Na}$ perspectiva junguiana, esse afastamento é um problema, uma vez que traz prejuízo aos próprios indivíduos. $\bigcirc$ artigo inicia com a análise de exemplos de religiões que proíbem relações entre pessoas do mesmo sexo. Posteriormente, são investigados os mitos e características psicológicas gerais da humanidade que fundamentam esses dogmas. Em seguida, descreve-se a relação da religião com certos mecanismos arcaicos de orientação psicológica. Concluise que quando imagens mitológicas, como o casal heterossexual divino, são interpretadas literalmente e não simbolicamente, formas diferentes de sexualidade podem ser desvalorizadas. Além disso, em diversas culturas, fenômenos naturais menos frequentes são considerados transgressões que

Conflito de interesses: O autor declara não haver nenhum interesse profissional ou pessoal que possa gerar conflito de interesses em relação a este manuscrito. exigem expiação. Nas religiões estudadas aqui, a homossexualidade foi incluída entre esses fenômenos, mesmo que isso não tenha acontecido em outras tradições. A soma das experiências religiosas que refletem a vivência da média, composta por maioria heterossexual, influencia os tabus sexuais da comunidade. Por fim, o artigo descreve o processo de individuação, uma forma de solucionar conflitos entre as características do indivíduo e os valores coletivos, possibilitando uma nova via de acesso aos símbolos das tradições religiosas, interpretando-os como símbolos da realização da própria individualidade.

\section{Descritores}

Psicologia da religião, homossexualidade, mitologia, psicologia junguiana.

Recebido: 21 mar 2020; $1^{\text {a }}$ revisão: 14 maio 2020; Aprovado: 25 ago 2020; Aprovado para publicação: 29 set 2020 


\title{
Considerations on the conflict between religion and homosexuality
}

\begin{abstract}
This article has investigated psychological aspects that influenced the conflict between homosexuality and religion throughout history, having C. G. Jung analytic psychology as main theoretical reference. This issue is relevant since the current ideological division in Brazil can lead those who back the LGBTI+ community to move away from religious symbols. From a Jungian perspective, this distancing is a problem, since it brings harm to the individuals themselves. The article starts with the analysis of examples of religions, which forbid relationships between people of the same sex. Subsequently, general myths and psychological characteristics of humanity were investigated, that underlie these dogmas. It proceeds to describe the relationship between religion and certain archaic mechanisms of psychological orientation. The conclusion arose that when mythological images, like the divine heterosexual couple, are understood literally and not symbolically, distinct sexuality forms may be devalued. Besides, in various cultures, less frequent natural phenomena are considered transgressions demanding expiation. In the religions studied here, homosexuality was included among these phenomena, even when this does not happen in other traditions. The set of religious experiences that reflect the experience of an average, heterosexual in its majority, influence the communities' sexual taboos. Finally, the article describes an individuation process, a way of solving the conflicts, between the individual's characteristics and the collective values, providing a new access path to the symbols of religious traditions, interpreting these as symbols of the accomplishment of one's own individuality.
\end{abstract}

\section{Descriptors}

Psychology of religion, homosexuality, mythology, Junguian psychology.

\section{Reflexiones sobre el conflicto entre religión y homosexualidad}

\section{Resumen}

Este artículo investigó aspectos psicológicos que influenciaron el conflicto entre homosexualidad y religión a lo largo de la historia, teniendo a la psicología analítica de C. G. Jung como principal referencia teórica. Esta cuestión es relevante, pues la presente división ideológica en Brasil puede llevar a los que 
apoyan a la comunidad LGBTI+ a alejarse de los símbolos religiosos. En la perspectiva Junguiana, ese alejamiento es un problema, porque trae perjuicio a los propios individuos. El artículo se inicia con el análisis de ejemplos de religiones que prohíben relaciones entre personas del mismo sexo. Posteriormente, se investigan los mitos y características psicológicas generales de la humanidad que fundamentan esos dogmas. Enseguida, se describe la relación de la religión con ciertos mecanismos arcaicos de orientación psicológica. Se concluye que cuando imágenes mitológicas, como la pareja heterosexual divina, se interpretan literalmente y no simbólicamente, formas diferentes de sexualidad pueden ser desvalorizadas. Además, en diversas culturas, fenómenos naturales menos frecuentes se consideran como transgresiones que exigen expiación. En las religiones estudiadas aquí, la homosexualidad fue incluida entre esos fenómenos, aunque eso no haya ocurrido en otras tradiciones. La suma de las experiencias religiosas que reflejan la vivencia de una media, en su mayoría heterosexual, influencia los tabús sexuales de la comunidad. Finalmente, el artículo describe el proceso de individuación, una forma de solucionar conflictos entre las características del individuo y los valores colectivos que posibilita una nueva vía de acceso a los símbolos de las tradiciones religiosas, interpretándolos como símbolos de la realización de la propia individualidad.

\section{Descriptores}

Psicología de la religión, homosexualidad, mitología, psicología junguiana.

\section{O problema}

A tarefa de abordar dois assuntos delicados como religião e homossexualidade em um artigo envolve muitas complicações. Entretanto, é inegável a importância que essa discussão assumiu atualmente. Além de vários outros fatores, o cenário político polarizado no Brasil inclui tensões entre os dois lados: pessoas religiosas e pessoas que apoiam e/ou fazem parte comunidade LGBTQI+.

problema do exagero das próprias qualidades e da desumanização de grupos diferentes é conhecido na psicologia. A tendência de tratar como inferiores pessoas de outros grupos como estrangeiros, pessoas de outra etnia, gênero ou geração, é considerada uma predisposição geral do ser humano (Harris \& Fiske, 2006; Boudjemadi et al., 2017). que, inclusive, sente prazer no sofrimento (schadenfreude) de grupos adversários (McLoughlin, 2018). Alguns estudos constataram essas características em crianças a partir dos dois anos de idade (Wang et al., 2019). Além disso, fatos e ideias que contrariam conceitos que os indivíduos sentem como parte de sua identidade desencadeiam emoções negativas e os fazem afirmar ainda mais 
enfaticamente sua posição inicial (Trevors, 2016). Assim, a psicologia tem contribuições para essa discussão.

apoio à diversidade de gênero é a prática padrão do psicólogo brasileiro. $\bigcirc$ Conselho Federal de Psicologia - CFP ([2014]) também se mostra a favor da liberdade religiosa e reconhece a importância das crenças. $\mathrm{Na}$ presente realidade política existem dificuldades em conciliar esses dois aspectos da vida humana.

Pessoas da comunidade LGBTQI+ que crescem em um contexto religioso têm maior probabilidade de apresentar ideação suicida (Gibbs \& Goldbach, 2015; Kralovec et al., 2014). A filiação e a participação em grupos religiosos são preditores de concepções negativas sobre a homossexualidade (Schulte \& Battle, 2004; Olson et al., 2006). Diante de tal cenário, pode-se acreditar que o abandono das ideias religiosas aliviaria o sofrimento psíquico das minorias sexuais.

Porém, de acordo com Jung, as atividades religiosas do ser humano têm base instintiva (Jung, 1957/2013) e sua depreciação pode trazer prejuízos. Os mitos que fundamentam os sistemas religiosos representam, de forma simbólica, processos inconscientes e sua recordação renova a conexão entre a consciência e o inconsciente, contribuindo para evitar a dissociação da personalidade (Jung, 1951/2013). Em outras palavras, "[...] a relação do indivíduo com Deus ou com os deuses impede que o homem perca o laço vital com as imagens reguladoras e os poderes instintivos do inconsciente" (Jung, 1954/2013, p. 318). Por isso, deve-se considerar cuidadosamente a função que um sistema religioso supre antes de se pensar em abandoná-lo, caso contrário o resultado será um retrocesso perigoso (Jung, 1912/[1952]/2013). É importante ressaltar que simplesmente participar de um sistema religioso não garante que o indivíduo vá além da mera formalidade, mantendo uma relação particular com as imagens reguladoras do inconsciente mesmo que, na visão de Jung, esse seja o sentido e a finalidade da religião (Jung, 1957/2013, p. 20).

Apesar disso, existem boas razões para desmistificar o mundo exterior. $\bigcirc$ concretismo, que coloca as ideias e sentimentos no mesmo plano dos objetos concretos (Jung, 1921/[1950]/2013), pode levar grupos a substituírem a realidade externa por um mito e combaterem uns aos outros violentamente. Um dos grupos se identifica com o herói perseguido e enxerga nos membros do outro partido o demônio que deve ser destruído para que o paraíso seja alcançado, o que é uma tentativa inconsciente de exterminar no outro as próprias falhas, como aconteceu, por exemplo, na perseguição aos judeus na Alemanha nazista (Jung, 1945/2013, p. 46).

Devido às possibilidades dessas manifestações negativas, cometeu-se o erro de se negar os aspectos saudáveis do pensamento mitológico e, a partir do século XIX, a ideologia materialista passou a dominar as universidades (Byington, 1985), enquanto os mitos e os sistemas religiosos passaram a ser vistos como fruto da ignorância (Peterson, 1999). 
Por outro lado Jung percebeu que, apesar dos mitos não nos dizerem muito sobre o funcionamento do mundo material, eles contêm representações de fatores psíquicos inconscientes, com os quais o indivíduo tem que se defrontar de alguma forma, sendo a religião e os sistemas religiosos maneiras de estabelecer essa relação (Jung, 1954/2013). Com isso, Jung não quis incitar ninguém a se converter a um credo específico, mas a compreender a função psicológica de tais símbolos, que surgem espontaneamente do inconsciente.

As pessoas, participantes de um credo ou não, que ignoram a importância e a função dos símbolos (que encontramos nos sonhos, nos mitos, na tradição religiosa etc.), correm o risco de se dissociar de certos processos inconscientes da psique, dos quais emergem as representações simbólicas (Jung, 1951/2013). Ou seja, quem ignora o fundo mitológico do pensamento humano vive imerso em um mito sem se dar conta, regredindo inconscientemente à interpretação mitológica da realidade de forma concretista. "Com efeito, quanto menos a consciência se lembra do inconsciente, tanto maior é o perigo de identificar-se com ele" (Jung, 1942/[1954]/2012, pp. 113-114).

As comunidades LGBTI+ do Ocidente são particularmente vulneráveis a esses problemas, pois foram excluídas dos valores coletivos de diversas religiões, tendo motivos para rejeitar a tradição. Entretanto, como dito acima, a rejeição total da tradição religiosa e seus símbolos pode afetar negativamente a relação do indivíduo com certos processos inconscientes, principalmente quando não se tem compreensão da função desses símbolos (Jung, 1951/2013). Por essa razão, é importante tratar desse assunto agora, em um momento de crescente polarização política que agrava ainda mais a tensão entre religião e homossexualidade.

O objetivo deste artigo é contribuir para evitar a desvalorização dos símbolos, para que a religião, enquanto função psicológica, continue exercendo seu papel de forma saudável, para o maior número de indivíduos possível. Olhar a religião a partir de um ponto de vista psicológico ajuda a superar certos conflitos, como aquele entre a fé e o saber (Jung, 1957/2013). Da mesma maneira, elucidar aspectos psicológicos que tenham relação com o conflito entre homossexualidade e religião também pode abrir uma nova perspectiva que possibilite uma solução.

\section{Religião e homossexualidade ao longo da história}

Na psicologia analítica, a religião é vista como uma atitude que envolve a consideração e a observação cuidadosas de fatores inconscientes numinosos (carregados de afeto), representados como espíritos, deuses, demônios etc., devido ao seu efeito dinâmico que se apodera do sujeito (Jung, 1937/2012). Para Jung, a experiência religiosa é o contato da consciência do indivíduo com estes fatores numinosos personificados (Miranda, 2019, p. 15). Já os sistemas religiosos, que foram chamados por Jung de confissões, são entendidos como "formas codificadas e dogmatizadas de experiências 
religiosas originárias" (Jung, 1937/2012, p. 21). Essa diferença entre religião (experiência direta) e sistema religioso (dogmas) deve ser mantida em mente, pois ambos os termos serão usados ao longo deste artigo.

Quanto ao termo homossexual, será usado para designar indivíduos cuja orientação sexual é voltada, principalmente, para relações com outros do mesmo sexo. Por mais que esse termo seja algo de origem recente, a homossexualidade foi motivo de discussão em muitas sociedades. Grande parte dos ocidentais está familiarizada com as advertências na Bíblia (2017), como em Levítico 18: 22 e em Levítico 20: 13, onde se diz que a relação sexual entre dois homens é um ato que deve ser punido com a morte.

O termo sodomia, cuja interpretação mais popular refere-se à relação sexual entre dois homens, também deriva de uma história bíblica: a de Sodoma e Gomorra. Nesta história, ambas as cidades foram destruídas por Deus, devido aos pecados de seus habitantes (Gênesis 19). O pecado mais grave foi associado à relação sexual entre homens.

No Alcorão, essa mesma história também serve como base para a condenação da homossexualidade. No Shura Ash-Shu'ara (26: 165-166), antes de Sodoma ser destruída, Lut (Ló) alerta os homens da cidade de que ter relações homossexuais é uma transgressão grave. Somente em 1861 a pena de morte para sodomia foi abolida na Inglaterra. Até então, a maioria dos condenados era formada por homens em relações homoafetivas, chamados pejorativamente de Molly (Frost, 2017).

No Novo Testamento também existem advertências contra a homossexualidade, como em Coríntios 6: 9-10; em 1 Timóteo 1: 9-11; e também em Romanos 1: 25-27. O Novo Testamento não incita a execução de pessoas que têm relações homossexuais - o castigo seria individual e de origem divina.

No hinduísmo, um texto tradicional, o Manusmriti, considera a homossexualidade masculina um crime que causa perda de casta (v. 175). No mesmo texto, punições também são aplicadas para mulheres que têm relações homossexuais (369-370). Na Índia, muitos Dharmashastras (livros da lei) reconhecem a existência da homossexualidade, mas nenhum deles aprova sua prática (Dedvdutt, 2009).

No budismo, a tradição Thevravada considera os pandakas (homossexuais e travestis nas significações mais populares) como espiritualmente inferiores, excluindo-os dos monastérios. Na Tailândia, país budista, a homossexualidade é explicada popularmente como uma punição cármica por desvio de conduta sexual em vidas passadas (Methangkun, 1986). Em um pronunciamento de 1997, em São Francisco (Estados Unidos), o Dalai-Lama, maior autoridade do budismo tibetano, afirmou que, do ponto de vista budista, a relação homossexual é considerada um desvio de conduta sexual (Harvey, 2000).

Os dados expostos servem como exemplo de sistemas religiosos que entraram em conflito com a homossexualidade. $\bigcirc$ autor tem consciência de que existem 
interpretações alternativas das escrituras que questionam essa oposição (Yip, 2005) e de que existiram culturas onde a homossexualidade, de alguma forma, tinha lugar na organização social. Porém, o foco aqui são os sistemas religiosos e as interpretações que condenam as relações entre pessoas do mesmo sexo.

A desaprovação da homossexualidade não é estritamente condicionada por crenças judaico-cristãs. Baseando-se na World Value Survey, foi observado que um dos fatores que aumenta a probabilidade de desaprovação da homossexualidade é fazer parte de um grupo religioso, independente do grupo ser católico, budista, hindu, cristão ortodoxo, protestante, mulçumano, ou não especificado, mesmo que alguns desses grupos sejam menos tolerantes que outros (Adamczyk \& Pitt, 2009). Isso justifica a necessidade de investigarmos características mais elementares da experiência religiosa que podem ter influenciado neste desenvolvimento.

Essas tradições têm raízes nas histórias de deuses, deusas e heróis, já que as religiões sempre são sustentadas por alguma espécie de mito. Por isso, serão analisados alguns desses mitos que evidenciam características gerais dessas histórias que possam ter relação com o problema aqui abordado.

\section{O casal divino}

$\mathrm{Na}$ visão junguiana, os mitos são "expressões simbólicas do drama inconsciente da alma" (Jung, 1935/2014, p. 14), que possuem uma estrutura universal, o que se torna evidente na semelhança temática entre mitos de diversas culturas ao redor do mundo e produtos espontâneos da psique individual, como sonhos, visões, delírios etc. (Jung, 1921/[1950]/2013). De acordo com Jung, a causa dessas similaridades repousa em fatores psicológicos coletivos, comuns a toda a humanidade, que ele denominou arquétipos (Jung, 1939a/2014).

Assim, os deuses dos mitos não são criados arbitrariamente, pois essas ideias têm bases arquetípicas; entretanto, o indivíduo "escolhe" quais deuses servir (Jung, 1937/2012, p. 109). É dito "escolhe" porque o maior valor atribuído a uma ideia arquetípica tem influência sobre qual atitude seria a mais adaptada, tanto às necessidades psicológicas como ao contexto ambiental, levando a uma "seleção natural de deuses" (Peterson, 1999, p. 227).

No Egito, um dos mitos que predominou foi o de Rá. Era dito que o deus entrava todas as noites no submundo como deus morto, lutava com a serpente Apófis e renascia ao amanhecer como Képhera (Budge, 1904, p. 179). Na religião acadiana, havia o Enuma Elish mito de criação babilônico - que conta como Marduk desmembrou a deusa-dragão Tiamat e construiu o universo a partir dos pedaços de seu corpo (Eliade, 1969/2010, p. 78-80). Na Grécia, havia o mito de Zeus, que enfrentou o dragão Tifão, subjugando-o e inaugurando uma nova era (Hesíodo, [s.d.], vv. 820-880). Na Índia, o rei dos deuses era Indra que, após matar com seu raio o dragão Vrtra, dissipou a escuridão que cobria o mundo (O Mahabharata: Udyoga Parva, [s.d.] pp. 21 - 
23). Esses personagens foram considerados, em suas respectivas culturas, como reis dos deuses, sendo não apenas objetos de veneração, como também modelos de conduta, além de terem sido influentes na formação dos sistemas religiosos citados anteriormente, o que os torna importantes para a presente discussão.

Um elemento comum nessas histórias da criação/renovação do cosmos era o casamento do deus com a deusa, após a destruição do monstro, deixando em evidência o arquétipo do casal divino, chamado por Jung de sízigia (Jung, 1936/2014, pp. 68-69). Por mais que hoje este casamento possa ser visto como algo simbólico, que representa a união da consciência com o inconsciente, ou a união de outros pares de opostos (Peterson, 1999), para o concretismo de muitos povos da época tratava-se literalmente de um casal heterossexual divino que habitava uma dimensão metafísica. Assim, a visão concretista, em vez de simbólica, do casal divino, pode ter influenciado na concepção de que a homossexualidade se opõe ao modelo dos deuses.

Entretanto, não deve se confundir as representações dos arquétipos, o que incluiria a imagem do casal de deuses heterossexuais, com os arquétipos em si, já que os arquétipos são fatores irrepresentáveis (Jung, 1946/2013). É possível pensar na união simbólica de elementos masculinos e femininos em outros pares de opostos, mesmo que não tenham relação direta com a sexualidade (Jung, 1936/2014), já que a sízigia faz parte de uma das categorias mais fundamentais que usamos para compreender a realidade (Peterson, 1999).

Portanto, da perspectiva simbólica, a sizígia também pode estar presente nas relações homoafetivas já que, como qualquer relação, envolve a projeção de conteúdos inconscientes no outro, oferecendo oportunidade para que estes conteúdos sejam integrados na consciência, levando ao autoconhecimento. Em outras palavras, em todas as relações, temos a possibilidade de conhecer aspectos desconhecidos de nós mesmos. Para a psicologia analítica, é essa conjunção entre consciência e inconsciente que é representada no símbolo da conjunção divina do par de opostos (Jung, 1956/2012). Para que ocorra essa união, que promove o desenvolvimento psíquico, é mais importante a qualidade da relação do que a forma:

Por isso não perguntamos o que alguém faz, mas como o faz. Se o faz por amor e no espírito do amor, então serve a um Deus; e o que quer que faça não cabe a nós julgá-lo, pois está enobrecido (Jung, 1928/2013, p. 123).

\section{A transgressão dos tabus}

Os mitos citados são desenvolvimentos de rituais, encenações que têm como objetivo organizar e direcionar os membros de uma comunidade (Peterson, 1999). O ritual é um recurso essencial utilizado pelas comunidades "primitivas" (termo usado no sentido de primordial e não como juízo de valor) 
para compreender o mundo, tornando o desconhecido em conhecido, ou caos em cosmos (Eliade, 1969/2010, p. 193). Como eventos raros ameaçam a compreensão de mundo dos primitivos, baseada em sua organização e conduta ritualísticas, eles se tornam tabus (interditos) que exigem expiação. Diz Jung:

É a regularidade dos acontecimentos ordinários que dá ao primitivo a sensação de segurança em seu mundo. Qualquer exceção the parece um ato perigoso de arbítrio que deve ser convenientemente propiciado, pois não se trata apenas da ruptura momentânea do costumeiro, mas ao mesmo tempo um presságio de outros acontecimentos adversos (Jung, 1931/2013, p. 68).

O não usual é considerado como imoral, já que moral é o que acontece com mais frequência (Jung, 1958/2013). Em diversas culturas primitivas ao redor do mundo, animais com comportamentos atípicos, gêmeos, crianças cujos dentes superiores nascem primeiro que os inferiores etc. devem ser mortos ou excluídos, de forma ritual, já que representam eventos incomuns que anunciam e causam desgraças (Lévy-Bruhl, 1922/2008). O argumento é o de que se tais exceções forem toleradas, a comunidade inteira perecerá pela ira dos espíritos (Lévy-Bruhl, 1922/2008), o que lembra a história de Sodoma e Gomorra, citada anteriormente, que foi base para condenação da homossexualidade no Ocidente.

Como a maioria dos estudos demográficos sobre a homossexualidade mostra, uma menor parcela da população (inferior a 7\%) identifica-se primariamente como homossexual (Richters et al., 2014; Haversath, et al., 2017; Gates, 2011 ; lbope, 2013). Assim, pode-se entender o porquê, na visão de muitos povos primitivos, da homossexualidade entrar na classe de fenômenos naturais menos frequentes, que necessitam de alguma forma de expiação.

Pode-se enxergar relações entre o mesmo mecanismo de organização operando por trás da formação de tabus e a proibição da homossexualidade. A transgressão do tabu era uma ameaça para a organização psicológica de toda a comunidade, tornando a preocupação com a conduta pessoal dos membros assunto de segurança pública (Lévy-Bruhl, 1922/2008). Assim, outra possível influência no conflito entre homossexualidade e religião é o fato desse comportamento ser menos frequente entre os seres humanos, o que entra em choque com certos mecanismos arcaicos de orientação psicológica.

\section{As reações do ser humano ao desconhecido}

É um engano considerar que a relação do primitivo com o desconhecido e irregular é completamente diferente daquela do ser humano contemporâneo. Como diz Jung: "[...] nosso cabedal de conhecimentos aumentou, mas não nossa inteligência. Por isso mostramo-nos tão pasmos e incapazes diante de ideias novas quanto os homens nos mais obscuros tempos da Antiguidade" (1912/[1952]/2013, p. 41 .). 
De acordo com Peterson (1999, p. 57), "a estabilidade de nossa cultura nos cegou para a verdadeira natureza de nossas respostas emocionais". Isso fez com que o indivíduo de hoje imaginasse ter se tornado uma espécie completamente diferente em um intervalo de centenas de anos. Porém, o ser humano de hoje ainda é extremamente sensível com relação às diferenças e ao imprevisível.

neurologista russo Sokolov observou a existência de um reflexo de orientação, que entra em ação quando o ser humano tem contato com uma informação desconhecida e/ou inesperada (Sokolov, 1969, citado por Peterson, 1999, p. 22). Essa reação fisiológica está relacionada com a interação entre as regiões cerebrais da amígdala e do hipocampo, que compara as expectativas com os eventos em curso (Peterson, 1999). Os afetos iniciais causados pelo encontro com o desconhecido são o alerta, o medo e a ansiedade (Peterson, 1999).

Isso está de acordo com o pensamento de Jung, que considerava a consciência moral (Gewissen) como uma reação instintiva àquilo que foge das normas, com o objetivo de recuperar a estabilidade psíquica do indivíduo (Jung, 1958/2013, p. 201). Jung considerava os tabus, incluindo os sexuais, como provenientes desse misoneísmo (medo do novo) e conservadorismo instintuais do ser humano, não sendo algo originado exclusivamente em fontes culturais externas (Jung, 1912/[1952]/2013).

Adamczyk \& Pitt (2009) observaram que quanto maior a estabilidade econômica e social de um país, mais o foco dos indivíduos muda da sobrevivência para a autoexpressão. Países orientados para a autoexpressão são mais tolerantes com a homossexualidade e a diversidade do que países orientados para a sobrevivência. Quando um país enfrenta algum tipo de crise econômica ou social, o foco muda para a sobrevivência e as pessoas tendem a voltar-se para o que é familiar, tornando-se menos tolerantes com grupos não-normativos.

Pode-se concluir que a estabilidade do ambiente e da cultura está relacionada com a intensidade das reações negativas àquilo que foge da norma descritas acima, tornando-as menos ou mais visíveis. Em termos junguianos, quando a consciência está em uma situação estável, a sombra que aparentemente desaparece, na verdade, encontra-se em estado latente (Jung, 1954/2014). A sombra é um conceito que designa tudo que o sujeito não reconhece em si e sempre o importuna, como seus traços de caráter inferiores e tendências incompatíveis com sua autoimagem (Jung, 1939b/2014).

É importante reconhecer essas características do comportamento humano, pois os que têm consciência da própria sombra estão em melhores condições de lidar com ela (Jung, 1946/2013) e menos propensos a projetá-la nos outros. Dessa forma, o confronto com a sombra deixa de ser um combate travado com terceiros, dando uma dimensão interior ao drama religioso. Assim, a atitude religiosa de confrontação interior funciona como um antídoto para a possessão coletiva pela sombra e suas consequências lamentáveis. 


\section{A individuação}

Os fatores descritos influenciaram o conflito entre homossexualidade e religião, sendo o objetivo principal deste artigo elucidá-los. Mas o que a psicologia pode fazer em relação àqueles que atualmente sofrem com este conflito?

Muitas denominações cristãs estão revendo sua posição sobre a homossexualidade (Tix, 2019), o que mostra uma mudança considerável da atitude do mundo ocidental em relação a esse assunto. Porém, assim como Jung (1957/2013), o autor deste artigo acredita que a solução para os conflitos entre a individualidade e os aspectos coletivos não está somente na mudança social, mas, principalmente, na experiência individual. As diferenças entre o indivíduo e os valores coletivos são realidades eternas, porque cada indivíduo é único.

Os sistemas religiosos, mesmo que importantes, não foram suficientes para resolver completamente os conflitos espirituais dos heterossexuais, então não há razão para imaginar que será diferente com os homossexuais. Para muitas pessoas, ser aceito pelo grupo é apenas parte do problema religioso, que também envolve um conflito de opostos internos. Nesses casos, é na experiência religiosa individual que se consegue ter um contato direto com o sentido dos símbolos religiosos e seu efeito unificador. Do ponto de vista psicológico, essa experiência se dá no contato com os arquétipos do inconsciente (Miranda, 2019).

A interação com os arquétipos, feita através das imagens que eles produzem, gradualmente aponta para os símbolos do si-mesmo, que transmitem uma imagem da personalidade total que busca se realizar (Jung, 1950/2014). Assim, na experiência religiosa, o autoconhecimento aumenta por meio da observação dos materiais produzidos espontaneamente pelo inconsciente, como sonhos, fantasias, visões etc. (Jung, 1957/2013), tornando o sujeito mais consciente de sua individualidade.

Essa vivência interior, em suas manifestações saudáveis, tem como consequência "um crescimento anímico duradouro no sentido de um amadurecimento e aprofundamento da personalidade" (Jung, 1950/2014, p. 354). Ou seja, o caminho indicado pelos símbolos surgidos durante as experiências religiosas são o desenvolvimento e a integração do ser humano total, a individuação (Jung, 1950/2014), uma forma de superar o conflito dos elementos opostos de um mesmo indivíduo, ao integrá-los em uma dinâmica criativa (Jung, 1950/2014). Durante esse processo, o sujeito adquire maior clareza de quem ele é, tornando-se menos dependente de terceiros para seu bem-estar psíquico. Para Jung, era justamente nessa ampliação da personalidade que se encontrava o fundamento da experiência religiosa (Jung, 1950/2014).

Sem a experiência religiosa individual como base, o dogma pode aumentar o vão que separa o indivíduo de si mesmo, seja ele hétero ou homossexual. Não 
que o indivíduo deva substituir o sistema religioso coletivo pelas suas experiências particulares, pois isto pode levar a um isolamento e a uma alienação patológicos (Jung, 1957/2012). Ao contrário, deve-se utilizar as visões obtidas pela exploração do inconsciente como base para compreender e estabelecer uma relação mais profunda com a tradição (Jung, 1957/2012). Assim, o indivíduo supera o conflito, pois, ao mesmo tempo em que integra suas características individuais, observando as imagens que sua psique produz, ele também ganha uma nova via de acesso aos símbolos da tradição.

É como se o drama da vida de Cristo de agora em diante fosse transposto para dentro do homem e tivesse o homem como seu portador vivo. Em consequência deste deslocamento, o acontecimento formulado no dogma é deslocado para o domínio atingido pela experiência e deste modo se torna reconhecível como processo de individuação (Jung, 1956/2012, p. 258).

Entretanto, para que esse processo de integração se inicie, é preciso aproximar-se de si mesmo, o que é uma tarefa dolorosa, da qual muitos preferem escapar projetando seus aspectos considerados negativos naqueles que estão ao redor (Jung, 1954/2014, p. 29). Por isso, o primeiro passo da individuação é o confronto com a própria sombra (Jung, 1954/2014), que personifica a parte "inferior" da personalidade do indivíduo. Inicialmente, a sombra acha-se projetada nos outros, e o reconhecimento dessas características em si mesmo não se dá sem resistências (Jung, 1951/2013). O reconhecimento das próprias falhas também é um antecessor comum das experiências religiosas (James, 1902).

É aqui que as ideologias que se concentram completamente na culpa do outro mostram porque estão fadadas ao fracasso. Elas roubam os indivíduos da possibilidade do confronto com a sombra, impossibilitando a ampliação da personalidade. São os judeus, os negros, os gays, as mulheres, os homens brancos, a esquerda, a direita e todos que não a própria pessoa que têm responsabilidade total pelos problemas. A inconsciência da própria sombra a deixa livre para causar barbaridades, enquanto os indivíduos se mantêm imaturos e irresponsáveis, tendo a ilusão de estarem fazendo o bem (Jung, 1946/2013). Isto é dizer que o caminho para a solução do conflito aqui abordado envolve o autoconhecimento.

Por mais que essa solução invoque o escárnio de ambos os lados, as guerras externas nas quais se insiste demonstraram sua esterilidade repetidas vezes. Estar completamente contra o lado esquerdo ou o direito de fora significa estar completamente contra o lado esquerdo ou direito de dentro. Só não se entende no outro o que não se entende em si mesmo. É a partir do momento em que se entende o outro dentro de si é que existe um verdadeiro diálogo. Só então pode-se dar um passo adiante e pensar, em conjunto, em verdadeiras soluções que beneficiem a todos. 


\section{Conclusão}

Pode-se concluir que a religião, na definição da psicologia analítica, não se opõe à homossexualidade. A oposição à homossexualidade é influenciada pelas reações emocionais que o ser humano tem com aquilo que foge do seu sistema de valores, que, em níveis arcaicos, são baseados no que acontece com maior frequência. Por ser a orientação sexual primária de uma parcela menor da população, a homossexualidade foi incluída, em algumas culturas, entre os fenômenos que desviam da norma e necessitam expiação, não sendo essa associação inevitável. Além disso, a experiência da média dos seres humanos, na maioria heterossexuais, dá origem às imagens arquetípicas retratadas nos mitos (Jung, 1937/2013), como o mito clássico do herói-deus que se casa com a princesa-deusa, e a interpretação concretista desses símbolos é outro fator que pode influenciar na rejeição da homossexualidade.

Neste artigo, demasiado breve considerando a complexidade do assunto, o autor espera ter apontado alguns fatos, históricos e psicológicos que influenciaram na oposição entre homossexualidade e religião e espera também ter oferecido pelo menos uma ideia geral de uma possível solução para tal conflito em nível interior, usando a perspectiva da psicologia analítica. Isto não deve criar a ilusão de que existe um método que garanta que as experiências relacionadas ao processo de individuação ocorram, já que há um grau de autonomia considerável nesses fenômenos. $\bigcirc$ melhor que podemos fazer, dentro de nossas limitações, é tentar um caminho de aproximação rumo a essas experiências (Jung, 1932/2012).

autor também espera ter demonstrado as razões para a preocupação com a possibilidade de afastamento dos símbolos ligados à religião, especificamente por parte de pessoas da comunidade LGBTI+ e seus apoiadores, já que este afastamento pode ter consequências negativas para os próprios indivíduos, caso eles não compreendam as necessidades que os símbolos suprem (Jung 1926/ 2013).

\section{Agradecimentos}

Meus sinceros agradecimentos à Ma. Ana Maria Caramujo Pires de Campos por ter sido minha orientadora na produção deste artigo.

\section{Referências}

Adamczyk, A., \& Pitt, C. (2009). Shaping attitudes about homosexuality: the role of religion and cultural context. Social Science Research, 38(20), 338351. https://doi.org/10.1016/i.ssresearch.2009.01.002.

Alcorão. Shura Ash-Shu'ara 26: 165-166. Recuperado em 18 de março de 2019, de https://quran.com/26/165-166. 
Barstow, A. (1978). The uses of archeology for women history: James Melaart's work on the Neolithic Goddess at Çatal Hüyük. Feminist Studies, 4(3), 7-18. https://doi.org/10.2307/3177535.

Bíblia de estudo integrada. (2017). (A. L. Tangerino, trad.). Rio de Janeiro: Thomas Nelson Brasil.

Boudjemadi, V., Demoulin, S., \& Bastart, J. (2017). Animalistic dehumanization of older people by younger ones: variations of humanness perceptions as a function of a target's age. Psychology and Aging, 32(3), 293-306. https://doi.org/10.1037/pag0000161.

Budge, E. W. (1904). The gods of the egyptians or studies in Egyptian Mythology (Volume I). Londres: Methuen \& Co.

Byington, C. (1985). As polaridades masculino e feminino, adulto e criança e o método simbólico na teoria do conhecimento. Núcleo de Estudos Junguianos. Recuperado em 18 de março de 2019, de https://www.pucsp.br/jung/portugues/publicacoes/artigos_as_polaridades_ masculino_feminino.html

Conselho Federal de Psicologia. ([2014]). Posicionamento do sistema Conselhos de Psicologia para a questão da psicologia, religião e espiritualidade. [Brasília, DF: CFP]. Recuperado em 15 de março de 2019, de https://site.cfp.org.br/wp-content/uploads/2014/06/Texto-aprovadona-APAF-maio-de-2013-Posicionamento-do-Sistema-Conselhos-dePsicologia-para-a-quest\%C3\%A3o-da-Psicologia-Religi\%C3\%A3o-eEspiritualidade-8-2.pdf.

Conselho Federal de Psicologia. (2018). Resolução n. 1, de 29 de janeiro de 2018. Recuperado em 15 de março de 2019, de https://site.cfp.org.br/wpcontent/uploads/2018/01/Resolu\%C3\%A7\%C3\%A3o-CFP-01-2018.pdf.

Devdutt, P. (2009). Did Homosexuality exist in ancient India? Recuperado em 18 de março de 2019, de http://devdutt.com/articles/appliedmythology/queer/did-homosexuality-exist-in-ancient-india.html

Eliade, M. (2010). História das crenças e das ideias religiosas I: da ldade da Pedra aos mistérios de Elêusis. Rio de Janeiro: Zahar. (Trabalho original publicado em 1976).

Frost, N. (2017 December 7). How the 18th-Century Gay Bar Survived and Thrived in a Deadly Environment: Wellcome to the Molly House. Atlas Obscura. Recuperado em 18 de março de 2019, de https://www.atlasobscura.com/articles/regency-gay-bar-molly-houses

Gates, G. J. (2011, April). How many people are lesbian, gay, bisexual, and transgender?. The Williams Institute. Recuperado em 18 de março de 2019, de https://williamsinstitute.law.ucla.edu/publications/how-manypeople-lgbt/. 
Gibbs, J. J., \& Goldbach J. (2015). Religious conflict, sexual identity, and suicidal behaviors among LGBT young adults. Archives of Suicide Research, 19(4), 472-488. https://doi.org/10.1080/13811118.2015.1004476.

Harris, L. T., \& Fiske, T. S. (2006). Dehumanising the lowest of the low: neuroimaging responses to extreme out-groups. Psychological Science, 17(10), 847-853. https://doi.org/10.1111/i.1467-9280.2006.01793.x

Haversath, J., Gärttner, K. M., Kliem, S., Vasterling, I., Strauss, B., \& Kröger, C. (2017). Sexual Behavior in Germany. Deutsches Ärzteblatt International, 114 (33-34), 545-550. https://doi.org/10.3238/arztebl.2017.0545.

Harvey, P. (2000). An introduction to Buddhist ethics. Cambridge: Cambridge University Press.

Hesíodo. (s.d.). Teogonia. Recuperado em 18 de março de 2019, de http://www.perseus.tufts.edu/hopper/text? doc =Perseus\%3Atext\%3A1999.0 $1.0130 \% 3$ Acard\%3D820

Ibope. (2013). Quase a metade dos internautas brasileiros concorda com o casamento gay. Recuperado em 16 de novembro de 2019, de https://web.archive.org/web/20140620164431/http://www.ibope.com.br/ pt-br/relacionamento/imprensa/releases/Paginas/Quase-a-metade-dosinternautas-brasileiros-concorda-com-o-casamento-gay-aspx.

James, W. (2009). The varieties of religious experiences. Adelaide: eBook@Adelaide. (Trabalho original publicado em 1902). Recuperado em 18 março de 2019, de https://ebooks.adelaide.edu.au/j/james/william/varieties/complete.html.

Jung, C. G. (2012). Relações entre a psicoterapia e a Direção Espiritual. In: Psicologia e religião ocidental e oriental: escritos diversos (OC, Vol. 11/6, $3 a$ ed. pp. 81 -104). Petrópolis, RJ: Vozes. (Trabalho original publicado em 1932).

Jung, C. G. (2012). Psicologia e religião ocidental e oriental: psicologia e religião (OC, Vol. 11/1, 11 la ed.). Petrópolis, RJ: Vozes. (Trabalho original publicado em 1937).

Jung, C. G. (2012). Psicologia e religião ocidental e oriental: o símbolo da transformação na missa (OC, Vol. 7a ed.). Petrópolis, RJ: Vozes. (Trabalho original publicado em 1942 [1954]).

Jung C. G. (2012). Mysterium coniunctionis: rex e regina, Adão e Eva, a conjunção (OC, Vol. 14/2, 3a ed.). Petrópolis, RJ: Vozes. (Trabalho original publicado em 1956).

Jung, C. G. (2012). Prefácio ao livro de Victor White: Deus e o inconsciente. In: Psicologia e religião ocidental e oriental: escritos diversos (OC, Vol. 11/6, 3a ed., pp. 53-64). Petrópolis, RJ: Vozes. (Trabalho original publicado em 1957). 
Jung, C. G. (2013). Símbolos da transformação (OC, Vol. 5, 9a ed.). Petrópolis, RJ: Vozes. (Trabalho original publicado em 1912, revisado e expandido em [1952]).

Jung, C. G. (2013). Tipos psicológicos (OC, Vol. 6, 7a ed.). Petrópolis, RJ: Vozes. (Trabalho original publicado em 1921, revisado em [1950]).

Jung C. G. (2013). Psicologia Analítca e Educação. In: $O$ desenvolvimento da personalidade (OC, Vol. 17, 14a ed., pp. 73-148). Petrópolis, RJ: Vozes. (Trabalho original publicado em 1926).

Jung, C. G. (2013). O problema amoroso do estudante. In: Civilização em mudança: civilização em transição (OC, Vol. 10/3, 6a ed., pp. 107-123). Petrópolis, RJ: Vozes. (Trabalho original publicado em 1928).

Jung, C. G. (2013). O homem arcaico. In: Civilização em mudança: civilização em transição (OC, Vol. 10/3, 6a ed., pp. 60-83). Petrópolis, RJ: Vozes. (Trabalho original publicado em 1931).

Jung, C. G. (2013). Determinantes psicológicas do comportamento humano. In: A dinâmica do inconsciente: a natureza da psique (OC, Vol. 8/2, 10a ed., pp.60-71). Petrópolis: Vozes. (Trabalho original publicado em 1937).

Jung, C. G. (2013). Depois da catástrofe. In: Civilização em mudança: aspectos do drama contemporâneo (OC, Vol. 10/2, 5a ed., pp. 28-51). Petrópolis, RJ: Vozes. (Trabalho original publicado em 1945).

Jung, C. G. (2013). Considerações teóricas sobre a natureza do psíquico. In: A dinâmica do inconsciente: a natureza da psique (OC, Vol. 8/2, 10a ed., pp. 104-185). Petrópolis: Vozes. (Trabalho original publicado em 1946).

Jung, C. G. (2013). A árvore filosófica. In: Estudos alquímicos (OC. Vol. 13, 4a ed.). Petrópolis, RJ: Vozes. (Trabalho original publicado em 1954, pp. 266-374).

Jung, C. G. (2013). Civilização em mudança: presente e futuro (OC, Vol. 10/1, 8a ed.). Petrópolis, RJ: Vozes. (Trabalho original publicado em 1957).

Jung, C. G. (2013). A consciência na visão psicológica. In: Civilização em mudança: civilização em transição (OC, Vol. 10/3, 6a ed., pp. 184-202). Petrópolis, RJ: Vozes. (Trabalho original publicado em 1958).

Jung, C. G. (2014). Sobre os arquétipos do inconsciente coletivo. In: Os arquétipos e o inconsciente coletivo (OC, Vol. 9/1, 11 a ed., pp. 11-50). Petrópolis, RJ: Vozes. (Trabalho original publicado em 1935).

Jung, C. G. (2014). O arquétipo com referência especial ao conceito de anima. In: Os arquétipos e o inconsciente coletivo (OC, Vol. 9/1, 11 a ed., pp. 63-81). Petrópolis, RJ: Vozes. (Trabalho original publicado em 1936).

Jung, C. G. (2014). Aspectos psicológicos do arquétipo materno. In: Os arquétipos e o inconsciente coletivo (OC, Vol. 9/1, 11 a ed., pp. 82-115). Petrópolis, RJ: Vozes. (Trabalho original publicado em 1939). 
Jung, C. G. (2014). A psicologia da figura do "trickster". In: Os arquétipos e o inconsciente coletivo (OC, Vol. 9/1, 11 a ed., pp. 256-273). Petrópolis, RJ: Vozes. (Trabalho original publicado em 1954).

Jung, C. G. (2014). Estudo empírico do processo de individuação. In: Os arquétipos e o inconsciente coletivo (OC, Vol. 9/1, 11 a ed.). Petrópolis, RJ: Vozes. (Trabalho original publicado em 1950).

Kralovec, K., Fartacek, C., Fartacek, R., \& Plöderl, M. (2014). Religion and suicide risk in lesbian, gay and bisexual Austrians. Journal of Religion and Health, 53(2), 413-423. https://doi.org/10.1007/s10943-012-9645-2

Lévy-Bruhl, L. (2008). A mentalidade primitiva. São Paulo: Paulus. (Trabalho original publicado em 1922).

Manusmirtii: the laws of Manu (G. Buhler, trad.). Recuperado em 18 de março de 2019, de https://www.islamawareness.net/Hinduism/manusmriti.pdf.

McLoughlin, N., Tipper, S. P., \& Over, H. (2018). Young children perceive less humanness in outgroup faces. Developmental Science, 21 (2), e12539. https://doi.org/10.1111/desc. 12539.

Methangkun, B. (1986). How can people be karthoeys?. Bangkok: Abhidhamma Foundation.

Miranda, P. (2019). C. G. Jung e a religião. Self - Revista do Instituto Junguiano de São Paulo, 4(1), e8. https://doi.org/10.21901/24483060/self-2019.vol04.0008.

O Mahabharata: Udyoga Parva (E. Meier, trad.). [s.d.]. [s.I.]: Distributed Proofing.

Olson, L. R., Cadge, W., \& Harrison, J. T. (2006). Religion and Public Opinion about Same-Sex Marriage. Social Science Quarterly, 87(2), 340360. https://doi.org/10.1111/i.1540-6237.2006.00384.x.

Peterson, J. B. (1999). Maps of meaning: the architecture of belief. New York: Routledge.

Richters, J., Altman, D., Badcock, P. B., Smith, A. M. A., de Visser, R. O., Grulich, A. E. et al. (2014). Sexual identity, sexual attraction and sexual experience: the second Australian study of health and relationships. Sexual Health, 11 (5), 451-460. https://doi.org/10.1071/SH14117.

Schulte, L. J., \& Battle, J. (2004). The relative importance of ethnicity and religion in predicting attitudes towards gays and lesbians. Journal of Homosexuality, 47(2), 127-142. https://doi.org/10.1300/J082v47n02_08

Sokolov, E. N. (1969). Handbook of contemporary Soviet psychology. New York: Basic Books.

Tix, A. (2019, Feb 18). Gays and the church: applying psychology to facilitate constructive dialogue. Psychology Today. Recuperado em 19 de março de 
2019, de https://www.psychologytoday.com/intl/blog/the-pursuitpeace/201902/gays-and-the-church.

Trevors, G. J., Muis, K. R., Pekrun, R., Sinatra, G. M., \& Winne, P. H. (2016). Identity and epistemic emotions during knowledge revision: a potential account for the backfire effect. Discourse Processes, 53(5-6), 339-370. https://doi.org/10.1080/0163853X.2015.1136507.

Wang, S., Lilienfeld S. O., Rochat, P. (2019). Schadenfreude deconstructed and reconstructed: a tripartite motivational model. New ldeas in Psychology, 52, $1-11$. https://doi.org/10.1016/i.newideapsych.2018.09.002.

Yip, A. T. (2005). Queering religious texts: na exploration of Britsh nonheterosexual Christians's and Muslim's strategy of constructing sexualityaffirming hermeneutics. Sociology, 39(1), 47-65. https://doi.org/10.1177/0038038505049000.

Minicurrículo: Guilherme Silva Gonçalves - Graduação em psicologia pelas Faculdades Metropolitanas Unidas (FMU). Terapeuta em análise aplicada do comportamento. Presidente e membro fundador da Liga Acadêmica de Pesquisas e Estudos Junguianos (LAPEJ) da FMU (2019-2020). Membro do departamento de literatura do Instituto Junguiano de São Paulo (IJUSP). E-mail: sg.guilherme00@gmail.com 